Efektivitas Layanan Bimbingan Kelompok....(Erfan Ramadhani)

\title{
EFEKTIVITAS LAYANAN BIMBINGAN KELOMPOK MENGGUNAKAN PENDEKATAN DISCOVERY LEARNING UNTUK MENGURANGI PROKRASTINASI AKADEMIK MAHASISWA MENGERJAKAN SKRIPSI
}

\author{
Oleh: Erfan Ramadhani ${ }^{1}$ Kurnia Sari ${ }^{2}$ \\ (Dosen Universitas PGRI Palembang) \\ Email : erfankonselor@gmail.com
}

\begin{abstract}
Abstrak
Berdasarkan temuan peneliti di lapangan, terungkap bahwa terdapat mahasiswa yang melakukan tindakan prokrastinasi akademik, prokrastinasi yang dilakukan dalam bentuk penundaan mengerjakan skripsi yang berdampak pada penyelesaian studi. Temuan peneliti ini menjadi indikasi bahwa mahasiswa memiliki masalah prokrastinasi akademik dalam mengerjakan skripsi. Salah satu upaya dalam mengatasi masalah tersebut adalah dengan cara pemberian layanan bimbingan kelompok menggunakan pendekatan discovery learning. Penelitian ini menggunakan metode kuantitatif. Jenis penelitian ini adalah eksperimen dengan rancangan one group pretest-posttest desain. Subjek penelitian ini adalah mahasiswa program studi bimbingan dan konseling yang di atas semester delapan. Instrumen penelitian ini menggunakan model skala likert, selanjutnya akan dianalisis menggunakan uji Wilcoxon Signed Ranks Test dengan bantuan SPSS versi 20.00. Temuan penelitian ini secara umum menunjukkan bahwa layanan bimbingan kelompok menggunakan pendekatan discovery learning efektif dalam mengurangi prokrastinasi akademik mahasiswa dalam mengerjakan skripsi. Selanjutnya, berdasarkan hasil penelitian ini dapat disarankan kepada pihak terkait agar dapat kerjasama dalam membantu mengatasi prokrastinasi akademik mahasiswa dalam mengerjakan skripsi.
\end{abstract}

Kata Kunci : Prokrastinasi Akademik, Layanan Bimbingan Kelompok, Discovery Learning

\section{EFFECTIVENESS OF GROUP MENTORING SERVICES USING DISCOVERY LEARNING APPROACH TO REDUCE ACADEMIC PROCRASTINATION OF STUDENTS DOING THE SCRIPTURE}

\begin{abstract}
Based on the findings of the researchers in the field, it was revealed that there were students who carried out academic procrastination, procrastination which was carried out in the form of delays in working on theses that were completed at the completion of the study. This research finding is an indication that students have problems with academic procrastination in working on their thesis. One effort to overcome this problem is by giving group guidance services using the discovery learning approach. This study uses quantitative methods. This
\end{abstract}


type of research is an experiment with the design of one gob pretest-posttest design. The subjects of this study were students of guidance and counseling study programs that were above the eighth semester. This research instrument uses a Likert scale model, then it will be analyzed using the Wilcoxon Signed Ranks Test with the help of SPSS version 20.00. The findings of this study generally indicate that group guidance services use discovery learning approach effective in reducing the academic procrastination of students in doing thesis. Furthermore, based on the results of this study can be suggested to the parties concerned in order to get cooperation in helping to overcome the academic procrastination of students in working on the thesis.

Keywords: Academic Procrastination, Group Guidance Services, Discovery Learning

\section{A. PENDAHULUAN}

Mahasiswa merupakan calon intelektual atau cendekiawan muda dalam lapisan masyarakat yang sering kali mendapatkan pandangan yang sangat positif. Mahasiswa dalam menjalani proses perkuliahan mereka dituntut untuk menjalankan pendidikan berupa pembelajaran. Selanjutnya, pada masa akhir semester mahasiswa akan menulis karya ilmiah berupa skripsi. Kurikulum yang diberikan kepada mahasiswa sudah sangat terstruktur dimana mereka akan menyelesaikan perkuliahan sampai dengan semester delapan, akan tetapi tidak sedikit ditemui mahasiswa yang melampai batas kurikulum yang telah ditentukan.

Berdasarkan hal tersebut di atas, mahasiswa yang mengalami masa studi yang lebih dari delapan semester terindikasi bahwa mahasiswa lalai dalam proses perkuliahan bahkan lalai dalam menyelesaikan tugas akhir atau skripsi. Proses perkuliahan menuntut mahasiswa untuk mendapakan nilai yang terstandar bahkan nilai yang bagus untuk setiap matakuliah yang diberikan. Untuk memperoleh nilai yang bagus mahasiswa diharapkan mengikuti perkuliahan dengan baik diantaranya hadir dalam proses perkuliahan, mengerjakan tugas dengan baik, aktif dalam proses perkuliahan bahkan mampu menjelaskan materi perkuliahan dengan baik di depan mahasiswa maupun dosen. Martin dan Osborne (dalam Yulistia, 2008) menjelaskan salah satu ciri mahasiswa yang berhasil adalah mahasiswa yang mampu mengatur dan membagi waktunya untuk melungkan mengerjakan 
Efektivitas Layanan Informasi....(Erfan Ramadhani)

tugas kuliah. Kemampuan untuk melakukan hal tersebut tidak dimiliki semua mahasiswa dikarenakan kebanyakan mahasiswa lalai dan melakukan tugastugasnya sebagai mahasiswa.

Kelalaian mahasiswa pada proses perkuliahan itu apabila terus terjadi maka itu akan berdanpak pada penyelesaian tugas akhir atau skripsi. Penundaan dalam melaksanakan tugas tersebut dikenal dengan prokrastinasi akademik. Prokrastinasi akademik merupakan prilaku yang tidak efektif dan efisien dalam memanfaatkan waktu dan adanya kecenderungan untuk tidak segera memulai suatu tindakan atau menunda tugas yang ingin dikerjakan sampai waktu berikutnya, sehingga prilaku penundaan tersebut dapat menghambat kesuksesan akademik individu itu sendiri. Selanjutnya, Tuckman (1990:3) menjelaskan "Procrastination results from combination of (1) disbelieving in one's own capability to perfrom a task, (2) being unable to postpone gratification, (3) assigning biame for one's own predicament to external sources”. Maksudnya kombinasi dari prokrastinasi adalah kemampuan diri sendiri untuk mengerjakan tugas, tidak mampu untuk menunda, dan menugaskan orang lain untuk mengerjakan tugasnya.

Fenomena prokrastinasi akademik umumnya terjadi karena adanya kecenderungan mahasiswa untuk melakukan penundaan dalam melaksanakan tugas yang akan dilaksanakan. Ellis dan Knaus (dalam Rumiani, 2006) mengungkapkan bahwa hampir 70\% mahasiswa di luar negeri melakukan prokrastinasi dalam makna luas.

Fenomena prokrastinasi akademik di atas, terjadi di program studi bimbingan dan konseling Fakultas Keguruan dan Ilmu Pendidikan Universitas PGRI Palembang terutama dalam mengerjakan skripsi. Berdasarkan hasil perolehan data yang didapatkan pada bagian akademik universitas PGRI Palembang terdapat sejumlah 212 mahasiswa bimbingan dan konseling angkatan 2012, sedangkan angkatan 2013 sejumlah 152 mahasiswa. Data yang diperoleh di bagian akademik tersebut diketahui bahwa mahasiswa angkatan 2012 sekarang sedang menjalani semester 10 yang seharusnya telah menyelesaikan pendidikan 
akan tetapi kenyataanya masih terdapat 24 mahasiswa yang belum menyelesaikan studinya.

Berdasarkan fenomena di atas, terindikasi bahwa 24 mahasiswa tersebut memiliki masalah dikarenakan mereka terlambat dalam menyelesaikan studi. Keterlambatan mahasiswa dalam menyelesaikan studi itu diindikasikan bahwa mahasiswa melakukan penunda-nundaan dalam melaksanakan tugas terutama dalam melaksanakan pengerjaan skripsi. Penundaan tersebut merupakan prokrastinasi akademik mahasiswa dalam penyelesaian studi yang berdampak pada terlambatnya dalam menyelesaikan studi yang mengakibatkan kerugian pada mahasiswa itu sendiri.

Selanjutnya, prokrastinasi akademik mahasiswa dalam mengerjakan skripsi dapat dilihat dari masih ditemukannya mahasiswa belum mengerjakan skripsi dikarenakan dengan sibuknya mengulang perkuliahan yang belum lulus. Berdasarkan fenomena tersebut dapat dikatakan bahwa mahasiswa melakukan prokrastinasi akademik bukan hanya pada penyelesaian skripsi saja akan tetapi melakukan penundaan dalam melaksanakan tugas perkulihan yang dijalaninya.

Masalah yang dialami mahasiswa berkaitan dengan prokrastinasi akademik tersebut sebaiknya diperbaiki. Cara memperbaiki masalah tersebut dapat diberikan bantuan layanan, layanan yang diperkirakan dapat mengatasi masalah tersebut adalah layanan bimbingan kelompok menggunakan pendekatan discovery learning. Layanan bimbingan kelompok merupakan salah satu layanan dari pelayanan bimbingan dan konseling, Sukardi (2002:48) menjelaskan "Layanan bimbingan kelompok adalah layanan bimbingan yang memungkinkan sejumlah individu secara bersama-sama memperoleh berbagai bahan dari narasumber tertentu (terutama dari konselor) yang berguna untuk menunjang kehidupannya sehari-hari baik sebagai individu, anggota keluarga, dan masyarakat dalam pengambilan keputusan”.

Bimbingan kelompok diartikan sebagai upaya untuk membimbing anggota kelompok agar menjadi lebih baik dan mandiri. Sedangkan pendekatan discovery learning merupakan pendekatan yang membuat layanan bimbingan kelompok 
Efektivitas Layanan Informasi....(Erfan Ramadhani)

menjadi inovatif yang mengarahkan anggota kelompok menemukan sendiri peyelesian masalah yang sedang dihadapi. Berdasarkan dari pengertian tersebut dapat disimpulkan bahwa masalah prokrastinasi akademik mahasiswa dalam menyelesaikan skripsi dapat dikurangi bahkan dapat diatasi dengan memberikan layanan bimbingan kelompok.

Berdasarkan uraian di atas, peneliti mencoba memberikan alternatif sebagai upaya membantu mahasiswa untuk mengurangi prokrastinasi akademik, dengan memanfaatkan layanan bimbingan kelompok menggunakan pendekatan discovery learning. Penelitian ini mencoba memanfaatkan materi-materi yang terkait dengan prokrastinasi akademik mahasiswa dalam menyelesaikan skripsi. Hal tersebut yang menjadi inti dari kajian penelitian, sehingga peneliti merumuskan penelitian ini dengan judul "Efektivitas Layanan Bimbingan Kelompok Menggunakan Pendekatan Discovery Learning untuk Mengurangi Prokrastinasi Akademik Mahasiswa Mengerjakan Skripsi”.

\section{B. METODOLOGI PENELITIAN}

Penelitian ini merupakan penelitian kuantitatif dengan metode penelitian eksperimen yang menggunakan desain Quasi Experimental. Bentuk Quasi Experimental yang digunakan dalam penelitian ini adalah one group pretest-posttest design. Subjek dalam penelitian ini sebanyak 10 orang mahasiswa yang masa studinya lebih dari delapan semester.

Instrumen yang digunakan dalam penelitian ini berbentuk skala model Likert dengan rentang skala lima. Instrumen penelitian menunjukkan tingkat validitas instrumen sebesar 0.361 dan reliabilitas dengan nilai Alpha Cronbach sebesar 0.873. Data yang telah terkumpul, dianalisis dengan cara menghitung skor rata-rata prokrastinasi akademik mahasiswa yang kemudian dideskripsikan menggunakan norma pengkategorian sebagai berikut.

Tabel 1. Kategorisasi Prokrastinasi Akademik Mahasiswa dalam Mengerjakan Skripsi

\begin{tabular}{|c|c|c|}
\hline \multicolumn{2}{|c|}{ Rentangan } & \multirow{2}{*}{ Kategori } \\
\hline Skor & $\%$ & Sangat Tinggi \\
\hline$\geq 134$ & $\geq 84$ & Tinggi \\
\hline $108-133$ & $68-83$ & \\
\hline
\end{tabular}

197 
Wahana Didaktika Vol. 16 No.2 Mei 2018 : 193-206

\begin{tabular}{|c|c|c|}
\hline \multicolumn{2}{|c|}{ Rentangan } & \multirow{2}{*}{ Kategori } \\
\hline Skor & $\%$ & \\
\hline $82-107$ & $52-67$ & Sedang \\
\hline $56-81$ & $36-51$ & Rendah \\
\hline$\leq 30$ & $\leq 35$ & Sangat Rendah \\
\hline
\end{tabular}

Data yang diperoleh selanjutnya dianalisis menggunakan uji Wilcoxon Signed Ranks Test dengan bantuan SPSS versi 20.00 .

\section{HASIL DAN PEMBAHASAN}

\section{Hasil Data Pretest}

Sesuai dengan tujuan dilakukannya pretest, yaitu untuk mengetahui gambaran awal prokrastinasi akademik mahasiswa mengerjakan skripsi sebelum diberikan perlakuan. Berikut disajikan kondisi pretest prokrastinasi akademik mahasiswa mengerjakan skripsi.

Tabel 2. Data Pretest

\begin{tabular}{|c|c|c|}
\hline \multicolumn{3}{|c|}{ Data Pretest } \\
\hline Kode Mahasiswa & Skor & Kategori \\
\hline E 1 & 141 & Sangat Tinggi \\
\hline E 2 & 128 & Tinggi \\
\hline E 3 & 139 & Sangat Tinggi \\
\hline E 4 & 129 & Tinggi \\
\hline E 5 & 129 & Tinggi \\
\hline E 6 & 129 & Tinggi \\
\hline E 7 & 129 & Tinggi \\
\hline E 8 & 129 & Tinggi \\
\hline E 9 & 137 & Sangat Tinggi \\
\hline E 10 & 132 & Tinggi \\
\hline Rata-Rata & $\mathbf{1 3 2 , 2}$ & Tinggi \\
\hline
\end{tabular}

Berdasarkan hasil pretest dari 10 orang mahasiswa yang memiliki prokrastinasi akademik dalam mengerjakan skripsi dalam kategori sangat tinggi sebanyak 3 orang, dalam kategori tinggi 2 orang. Berdasarkan data tersebut dapat disimpulkan bahwa prokrastinasi akademik mahasiswa berada dalam kategori sangat tinggi dengan nilai rata-rata sebesar 132,2. 
Efektivitas Layanan Informasi....(Erfan Ramadhani)

\section{Hasil Data Posttest}

Tabel 2. Data Posttest

\begin{tabular}{|c|c|c|}
\hline \multicolumn{3}{|c|}{ Data Posttest } \\
\hline Kode Mahasiswa & Skor & Kategori \\
\hline E 1 & 106 & Sedang \\
\hline E 2 & 111 & Tinggi \\
\hline E 3 & 123 & Tinggi \\
\hline E 4 & 107 & Sedang \\
\hline E 5 & 112 & Tinggi \\
\hline E 6 & 107 & Sedang \\
\hline E 7 & 110 & Tinggi \\
\hline E 8 & 112 & Tinggi \\
\hline E 9 & 117 & Tinggi \\
\hline E 10 & 123 & Tinggi \\
\hline Rata-Rata & $\mathbf{1 1 2 , 8}$ & Tinggi \\
\hline
\end{tabular}

Berdasarkan hasil posttest dari 10 orang mahasiswa yang memiliki prokrastinasi akademik dalam mengerjakan skripsi dalam kategori tinggi 7 orang sedangkan dalam kategori sedang 3 orang. Berdasarkan data tersebut dapat disimpulkan bahwa prokrastinasi akademik mahasiswa berada dalam kategori tinggi dengan nilai rata-rata sebesar 112,8. Hasil pretest dan hasil posttest menunjukan bahwa terdapat penurunan skor secara rata-rata sebesar 19,4. Berdasarkan hasil tersebut dapat disimpulkan bahwa pelaksanaan layanan bimbingan kelompok dapat mengurangi prokrastinasi akademik mahasiswa dalam mengerjakan skripsi secara matematis.

\section{Hasil Prokrastinasi Akademik Mahasiswa Pretest dan Posttest}

Data penelitan yang diperoleh berdasarkan pengadministrasian instrumen yang diberikan kepada 10 orang mahasiswa sebelum (pretest) dan sesudah perlakukan (posttest). Berikut akan disajikan skor masing-masing prokrastinasi akademik mahasiswa dalam mengerjakan skripsi sebelum dan sesudah perlakuan.

Tabel 3. Data Perbandingan nilai Pretest dan Posttest

\begin{tabular}{|c|c|c|c|c|c|}
\hline \multirow{2}{*}{ No } & \multirow{2}{*}{$\begin{array}{c}\text { Kode } \\
\text { Mahasiswa }\end{array}$} & \multicolumn{2}{|c|}{ Pretest } & \multicolumn{2}{c|}{ Postest } \\
\cline { 3 - 6 } & Skor & Kategori & Skor & Kategori \\
\hline 1. & E 1 & 141 & Sangat Tinggi & 106 & Sedang \\
\hline 2. & E 2 & 128 & Tinggi & 111 & Tinggi \\
\hline 3. & E 3 & 139 & Sangat Tinggi & 123 & Tinggi \\
\hline 4. & E 4 & 129 & Tinggi & 107 & Sedang \\
\hline
\end{tabular}




\begin{tabular}{|c|c|c|c|c|c|}
\hline \multirow{2}{*}{ No } & \multirow{2}{*}{$\begin{array}{c}\text { Kode } \\
\text { Mahasiswa }\end{array}$} & \multicolumn{2}{|c|}{ Pretest } & \multicolumn{2}{c|}{ Postest } \\
\cline { 3 - 6 } & Skor & Kategori & Skor & Kategori \\
\hline 5. & E 5 & 129 & Tinggi & 112 & Tinggi \\
\hline 6. & E 6 & 129 & Tinggi & 107 & Sedang \\
\hline 7. & E 7 & 129 & Tinggi & 110 & Tinggi \\
\hline 8. & E 8 & 129 & Tinggi & 112 & Tinggi \\
\hline 9. & E 9 & 137 & Sangat Tinggi & 117 & Tinggi \\
\hline 10. & E 10 & 132 & Tinggi & 123 & Tinggi \\
\hline \multicolumn{2}{r}{ Rata-Rata } & $\mathbf{1 3 2 , 2}$ & Tinggi & $\mathbf{1 1 2 , 8}$ & Tinggi \\
\hline
\end{tabular}

Berdasarkan tabel di atas terlihat jelas bahwa prokrastinasi akademik mahasiswa dalam mengerjakan skripsi mengalami penurunan setalah diberikan layanan informasi. Sebelumnya rata-rata skor prokrastinasi akademik mahasiswa dalam mengerjakan skripsi sebesar 132,2 dan berada pada kategori tinggi, setalah diberikan perlakuan maka skor prokrastinasi akademik mahasiswa dalam mengerjakan skripsi sebesar 110,9 dan tetap berada pada kategori tinggi, akan tetapi terdapat penurunan skor secara rata-rata sebesar 19,4. Penerunan rata-rata yang terjadi merupakan efek dari perlakuan layanan bimbingan kelompok menggunakan pendekatan discovery learning.

Setelah diberikan layanan bimbingan kelompok data hasil posttest mengalami penurunan jumlah skor atau mengalami perubahan. Berdasarkan hal tersebut maka untuk melihat kondisi masing-masing prokrastinasi akademik mahasiswa dapat dilihat pada gambar berikut.

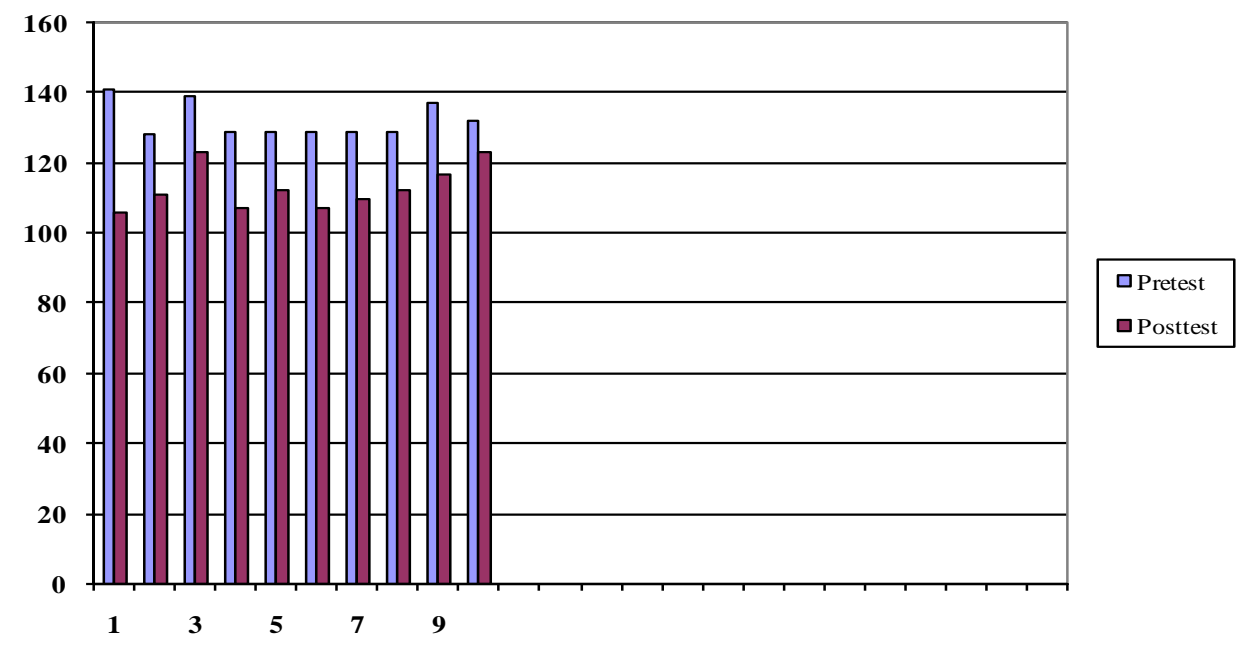

Gambar 1. Histogram Hasil Pretest dan Posttest Prokrastinasi Akademik Mahasiswa 
Efektivitas Layanan Informasi....(Erfan Ramadhani)

Berdasarkan gambar di atas, dapat diketahui bahwa terdapat perbedaan prokrastinasi akademik mahasiswa setelah diberikan layanan bimbingan kelompok menggunakan pendekatan discovery learning. Dari 10 mahasiswa yang mendapatkan perlakuan terdapat perubahan skor prokrastinasi akademik dalam mengerjakan skripsi, sebanyak 10 orang mahasiswa mengalami penurunan skor.

\section{PEMBAHASAN}

Temuan penelitian ini adalah terdapat perbedaan yang signifikan prokrastinasi akademik mahasiswa dalam mengerjakan skripsi sebelum dan setelah diberikan perlakuan layanan bimbingan kelompok menggunakan pendekatan discovery learning. Selanjutnya agar dapat dipahami secara konseptual hasil penelitian ini maka akan dibahas secara mendalam.

\section{Prokrastinasi Akademik Mahasiswa}

Hasil penelitian menjukan bahawa prokrastinasi akademik mahasiswa dalam mengerjakan skripsi berada dalam kategori tinggi dengan nilai rata-rata sebesar 132,2. Berdasarkan hasil data tersebut dapat ditarik kesimpulan bahwa secara umum mahaiswa yang masa studinya lebih dari semseter delapan merupakan mahasiswa yang memiliki masalah dalam penyelesaian skripsi. Permasalahan tersebut merupakan indikasi dari lambatnya mahasiswa mengerjakan skripsi bahkan melakukan penunda-nundaan dalam mengerjakannya dan sering dikenal dengan prokrastinasi akademik.

Tuckman (1990) menjelaskan "Procrastination is attitudinally and behaviorally”. Maksudnya, penundaan adalah sikap dan perilaku. Sikap dan perilaku penundaan yang ada pada diri mahasiswa ketika memulai dan mengerjakan tugas, yang terdiri dari tugas individu maupun tugas kelompok yang diberikan oleh dosen, dengan adanya kebiasaan tersebut maka berdampak pada penunda-nundaan dalam mengerjakan tugas akhir atau skripsi. Penundaan dalam mengerjakan skripsi akan sangat berdanpak pada masadepan mahasiswa dan juga berdanpak negatif bagi mahasiswa danpak tersebut sering dikenal dengan prokrastinasi disfungsional, yaitu apabila mahasiswa menunda dalam 
mengerjakan skripsi dan tidak memiliki keinginan untuk menyelesaikannya. Penundaan pula ada yang berdanpak positif atau sering dikenal dengan prokrastinasi fungsional, yaitu apabila seseorang melakukan penundaan disertai dengan alasan yang kuat serta memiliki tujuan yang pasti sehingga meminimalisir kerugian bahkan berguna untuk melakukan suatu upaya agar tugas dapat terselesaikan dengan baik (Risnawita dan Ghufron, 2014).

\section{Prokrastinasi Akademik Mahasiswa dalam Mengerjakan Skripsi Sebelum diberikan Perlakuan.}

Hasil diskripsi data pretest menunjukkan bahwa tingkat prokrastinasi akademik mahasiswa berada pada kategori sanggat tinggi dengan sekor 132,2, hal tersebut apabila tidak diberikan bantuan ataupun arahan akan berdanpak negatif terhadap masadepan mahasiswa. Prokrastiniasi merupakan suatu penundaan dalam mengerjakan tugas, penundaaan tersebut dilakukan secara berulang-ulang oleh mahasiswa. Penundaan yang dilakukan merupakan suatu kebiasaan yang harus dirubah karna kebiasaan tersebut merupakan kebiasaan yang sangat buruk dan memiliki efek yang tidak baik.

Mahasiswa yang melakukan penundaan biasanya berpikir sangat irrasional hal ini sesuai dengan pendapat Indra (2015:119) “Mahasiswa yang cenderung melakukan prokrastinasi akademik adalah mahasiswa yang memiliki pemikiran yang irrasional dalam pengaturan waktu serta cenderung melakukan hal-hal yang tidak bermanfaat daripada untuk belajar atau mengerjakan tugas”. Berdasarkan hal tersebut dapat disimpulkan bahwa prokrastinasi merupakan perbuatan yang negatif dan sanggat buruk apabila tidak diatasi dengan baik.

\section{Prokrastinasi Akademik Mahasiswa dalam Mengerjakan Skripsi Setelah diberikan Perlakuan}

Prokrastinasi akademik yang sering disebut penundaan yang dilakukan sebagai cara untuk menghindari tugas akademik yang dirasa tidak menyenangkan dan sulit dilakukan. Tuckman (1990:3) menjelaskan "Procrastination results from 
Efektivitas Layanan Informasi....(Erfan Ramadhani)

combination of (1) disbelieving in one's own capability to perfrom a task, (2) being unable to postpone gratification, (3) assigning biame for one's own predicament to external sources". Maksudnya kombinasi dari prokrastinasi adalah kemampuan diri sendiri untuk mengerjakan tugas, tidak mampu untuk menunda, dan menugaskan orang lain untuk mengerjakan tugasnya. Berdasarkan penjelasan di atas dapat dipahami bahwa prokrastinasi akademik merupakan hal yang negatif. Prokrastinasi juga merupakan perilaku yang sangat tidak baik diantaranya adalah perilaku yang lalai, ragu-ragu, kurang tepat waktu serta kurang perencanaan yang matang.

Selanjutnya, hasil deskripsi data menunjukkan tingkat proktrastinasi akademik mahasiswa dalam mengerjakan skripsi mengalami penurunan skor secara rata-rata dari sanggat tinggi menjadi tinggi, dari skor 132,2 menjadi 112,8 dan memiliki rerata penurunan sebesar 19,4. Hal tersebut merpakan efek dari pemberian layanan bimbingan kelompok menggunakan pendekatan discovery learning, layanan bimbingan kelompok menggunakan pendekatan discovery learning merupakan suatu layanan yang dapat memberikan pemahaman serta kemampuan kepada mahasiswa terhadap suatu hal-hal yang baru. Romlah (2006:3) adalah proses pemberian bantuan yang diberikan pada individu dalam situasi kelompok, yang ditujukan untuk mencegah timbulnya masalah pada siswa dan mengembangkan potensi siswa. Selanjutnya, Ramadhani, E. (2016) mengungkapkan bahwa layanan informasi menggunakan pendekatan discovery learning dapat meningkatkan aspirasi karier siswa. Berdasarkan hal tersebut dapat disimpulkan bahwa layanan informasi dan layanan bimbingan kelompok apabila dipadukan dengan pendekatan discovery learning dapat memberikan efek yang signifikan.

\section{Perbedaan Prokrastinasi Akademik Mahasiswa (Pretest dan Posttest)}

Prokrastinasi akademik mahasiswa merupakan suatu perilaku yang tidak baik, hal ini dikarenakan prokrastinasi merupakan penundaan dalam mengerjakan suatu tugas, tugas yang dimaksud adalah menyelesaikan skripsi. Penundaan yang 
dilakukan akan berdanpak negatif pada masadepan mahasiswa yang diantaranya adalah tidak terselesainya tugas, terlambat dalam menyelesaikan studi bahkan terancam dikeluarkan karena masa studi yang sudah habis.

Penelitian ini menungkap gambaran prokrastiniasi akademik mahasiswa dalam mengerjakan skripsi, sebelum diberikan perlakuan rata-rata tingkat prokrastinasi akademik mahasiswa dalam mengerjakan skripsi berada pada kategori tinggi dengan nilai skor 132,2 dan setelah diberikan perlakukan dengan mengunakan layanan bimbingan kelompok maka tingkat prokrasinasi akademik mahasiswa dalam mengerjakan skripsi menjadi menurun ke kategori tinggi dengan nilai rata-rata skor sebesar 112,8. Berdasarkan hal tersebut dapat diartikan bahwa perlakukan yang diberikan berupan layanan bimbingan kelompok kepada mahasiswa dapat mengurangi prokrastinasi akademik dalam mengerjakan skripsi dengan selisih skor sebesar 19,4.

Selanjutnya Ramadhani, E, Putri, R.D, \& Istiqoma, V.A. (2018) mengungkapkan bahwa layanan informasi efektif dalam mengurangi tingkat prokrastinasi akademik mahasiswa dalam mengerjakan skripsi. Penelitian Ramadhani, E, Putri, R.D, \& Istiqoma, V.A. (2018) merupakan suatu rujukan bagi penelitian ini dan hasilnya sama-sama efektif dalam mengurangi tingkat prokrastinasi akademik mahasiswa dalam mengerjakan skripsi.

Berdasarkan penjelasan di atas, dpat dipahami bahwa masalah prokrastinasi akademik mahasiswa dalam mengerjakan skripsi dapat di atasi dengan diberikan layanan bimbingan kelompok yang berkaitan dengan masalah penundaan dalam mengerjakan skripsi. Selanjutnya, Sukardi (2008:64) mengungkapkan bahwa terdapat tiga fungsi yaitu dari layanan bimbingan kelompok, "Fungsi informatif, fungsi pengembangan, fungsi preventif dan kreatif”. Melalui bimbingan kelompok, individu dapat memperoleh pemahaman tentang informasi yang dibahas sehingga dapat mengembangkan KES dan mencegah terjadi KES-T, berdasarkan hal tersebut mahasiswa mampu menemukan jalan keluar dari permasalahan yang dihadapinya yang berkaitan dalam mengerjakan skripsi 
Efektivitas Layanan Informasi....(Erfan Ramadhani)

\section{SIMPULAN}

Berdasarkan hasil penelitian yang diperoleh, dan setelah melakukan analisis statistik serta uji hipotesis, maka dapat disimpulkan secara umum bahwa layanan bimbingan kelompok menggunakan pendekatan discovery learning dapat mengurangi prokrastinasi akademik mahasiswa dalam mengerjakan skripsi. Secara khusus temuan penelitian ini adalah sebagai berikut.

1. Terdapat perbedaan yang signifikan prokrastinasi akademik mahasiswa sebelum dan setelah diberikan layanan bimbingan kelompok menggunakan pendekatan discovery learning.

2. Layanan bimbingan kelompok menggunakan pendekatan discovery learning dinilai efektif dalam mengurangi prokrastinasi akademik mahasiswa dalam mengerjakan skripsi.

3. Prokrastinasi akademik mahasiswa sebelum diberikan layanan bimbingan kelompok menggunakan pendekatan discovery learning masuk dalam kategori tinggi dan setelah diberikan layanan bimbingan kelompok tingkat prokrastinasi akademik mahasiswa mengalami penurunan.

\section{DAFTAR PUSTAKA}

Indra, S. 2015. "Efektivitas Layanan Informasi dengan Menggunakan Teknik Team Assisted Individualization untuk Mengurangi Prokrastinasi Akademik”. Tesis. Program Studi S2 Bimbingan dan Konseling Fakultas Ilmu Pendidikan Universitas Negeri Padang.

Ramadhani, E. 2016. Efektivitas Layanan Informasi Menggunakan Pendekatan Discovery Learning dalam Meningkatkan Aspirasi Karier Siswa. Tesis tidak diterbitkan. Prodi S2 BK FIP UNP.

Ramadhani, E, Putri, R.D, \& Istiqoma, V.A. 2018. Effectiveness of Information Services to Reduce Student Academic Procrastination in Working Thesis (Experiment Study on Student of Guidance and Counseling Universitas PGRI Palembang). Prosiding Dosen Universitas PGRI Palembang Edisi 18. Jurnal Dosen Universitas PGRI Palembang.

Risnawita, R., \& Ghufron, M.N. 2014. Teori-teori Psikologi. Jakarta: Ar-Ruzz Media.

Romlah. 2006. Teori dan Praktek Informasi. Malang: UNM. 
Rumiani. 2006. Prokrastinasi Akademik Ditinjau Dari Motivasi Berprestasi dan Stres Mahasiswa. Jurnal Psikologi Universitas Diponogoro Vol.3 No. 2, 1617.

Sukardi. 2002. Pengantar Pelaksanaan Program Bimbingan dan Konseling di Sekolah. Jakarta: Rineka Cipta.

Sukardi. 2008. Pengantar Pelaksanaan Program Bimbingan dan Konseling di Sekolah. Jakarta: Rineka Cipta.

Tuckman. 1990. "Measuring Procrastination Attitudinally and Behaviorally". Journal Procrastination Scale. Florida State University.

Yulistia. 2008. Panduan Bagi Fasilitator PDPT OBM 2008. Http://www.clr.ui.edu/wp-content/uploads/2008/07/panduan-bagifasilitator.pdf. Diakses pada tanggal 15 Desember 2016. 